\title{
A Functionalized Paper Strip-Based Platform for Rapid Detection of Anticancer Drug Concentrations
}

\author{
Goran M. Stojanović ${ }^{(D)}{ }^{1}$ Tijana Kojić, ${ }^{1}$ Mitar Simić ${ }^{(D},{ }^{1}$ Milan Radovanović, ${ }^{1}$ Sanja Panić, ${ }^{2}$ \\ Vladimir V. Srdić, ${ }^{2}$ Saša Vukmirović, ${ }^{3}$ Gaewyn Ellison $\mathbb{D}^{\mathbb{D},}{ }^{4,5}$ and Hani Al-Salami $\mathbb{D}^{4,6}$ \\ ${ }^{1}$ Faculty of Technical Sciences, University of Novi Sad, Novi Sad, Serbia \\ ${ }^{2}$ Faculty of Technology, University of Novi Sad, Novi Sad, Serbia \\ ${ }^{3}$ Faculty of Medicine, University of Novi Sad, Novi Sad, Serbia \\ ${ }^{4}$ Biotechnology and Drug Development Research Laboratory, School of Pharmacy and Biomedical Sciences, Curtin Health Innovation \\ Research Institute, Curtin University, Perth, Australia \\ ${ }^{5}$ School of Molecular and Life Sciences, Curtin University, Perth, Australia \\ ${ }^{6}$ Hearing Therapeutics, the Ear Science Institute Australia, Queen Elizabeth II Medical Centre, Nedlands 6009, Perth, \\ Western Australia, Australia
}

Correspondence should be addressed to Mitar Simić; mitar.simic@uns.ac.rs

Received 9 February 2021; Accepted 4 May 2021; Published 11 June 2021

Academic Editor: J.G. Manjunatha

Copyright (C) 2021 Goran M. Stojanović et al. This is an open access article distributed under the Creative Commons Attribution License, which permits unrestricted use, distribution, and reproduction in any medium, provided the original work is properly cited.

\begin{abstract}
This article presents a compact, low-cost, robust, and flexible test platform for determining the concentration of drugs in fluids. This device is based on a PVC foil card containing copper conductive foils in which disposable paper test strips are inserted. The paper test strips are overlaid with deposition of multiwalled carbon nanotubes (MWCNTs) acting as a sensing layer. When a paper test strip is inserted into the test card, the conductive path between two copper lines is established. A drop of test fluid on the sensing MWCNT layer changes the conductivity in a concentration-dependent manner, enabling calculation of the drug concentration after measurement of the electrical resistance at the copper terminals. An equivalent electrical circuit was also proposed to model the response of the fabricated sensor. It was shown that model parameters are dependent on the concentration of the cytostatic drug methotrexate. Additionally, the fabricated sensor demonstrated the ability to differentiate the same concentration of methotrexate and cyclophosphamide. The complete readout electronics and polynomial transfer function for calculating drug concentrations were also developed and are presented.
\end{abstract}

\section{Introduction}

During the previous decade, the use of novel technologies has been widely exploited in applied science in order to create portable, user-friendly, and point-of-care sensing platforms. Different materials for sensor fabrication have been considered including unconventional substrates, such as paper, due to its advantages of being of low cost, environmental friendliness, and ease of application.

Paper-based microfluidic devices represent a practical solution for testing in a variety of domains such as clinical, environmental, food, and forensic applications $[1,2]$. These devices have advantages, such as easy fabrication, simple operation, and chemical and biological inertness. Paperbased devices for measuring creatinine in urine and blood were presented in $[3,4]$, respectively. Thanks to the paper substrate, results can be produced rapidly and used by untrained staff [5]. Cellulose-based materials have been used in biosensors [6, 7] or diagnostic applications [8]. Materials such as metal nanoparticles or carbon nanotubes (CNTs) can be applied for modification of biosensor performance [9]. Nanoparticle-based biosensors for measuring creatinine in urine were reported in [10]. The detection mechanism is based on creatinine-mediated aggregation of the $\mathrm{cc}-\mathrm{Ag}$ 
nanoparticles (NPs) at $\mathrm{pH} 12$, which causes color change. The presented approach in [10] requires no sample pretreatment or surface modification of the AgNPs. Gold nanoparticles deposited on indium tin oxide substrate, together with a piece of filter paper, were used in [11] to construct an analytical device for the detection of hydrogen peroxide. The working electrode presented in [11] demonstrated a low detection limit, it was manufactured to be disposable, and the volume of sample required was very small (less than $10 \mu \mathrm{L}$ ). A microfluidic chip, presented in [12], was manufactured using paper and ssDNA-functionalized graphene oxide (GO), to determine different types of chemical contaminants in food. The GO helped to develop the device that can be used for multiplex detection of heavy metal antibiotic residues in food. A single-walled CNT (SWCNT) electrode and nafion modified membrane were used in [13] to manufacture a fluidic device for detection of the drug acetaminophen. Negatively charged nafion was applied to create a negative charge on the nitrocellulose membrane, and AuNPs were deposited on the SWCNT-based electrode to improve the electrochemical characteristics, e.g., to get a specific acetaminophen oxidation peak. Metallic electrodes can be deposited on the paper using various technologies, e.g., pencil drawing [14], pen-on-paper [15], or screen printing methods [16]. A paper-based microfluidic device which can detect drugs (cocaine, codeine, and methamphetamine) using compound-specific aptamers and gold nanoparticles by means of a colorimetric principle was reported in [17]. An optical readout system presented in [18] was based on the lab-on-a-paper concept and had the possibility not only to identify the presence of cocaine but also to detect the concentration of cocaine in the tested sample. Paper sensing strips that change colors while screening for drugs in an aquatic environment were presented for quinolone [19] and oxytetracycline [20] antibiotics. A glucose electrochemical biosensor using wax-defined paper with diluted carbon ink was presented in [21]. A biosensor for the detection of mercury pollution in cosmetics, based on visual effects on a disk-shaped piece of filter paper, was developed in [22]. A paper-based device created by graphite pencil leads and modified with nafion was proposed in [23] and applied for the detection of pyocyanin, a biomarker for Pseudomonas aeruginosa. Cellulose-based strips were manufactured by the method described in [24], for glucose concentration detection via color changing. An enzyme-based test which can detect lactose in low concentrations in solid samples and complex mixtures was reported in [25]. A microfluidic system that uses paper as a sensing region for quantitative analysis of electrolytes in tears through a readout device and a smartphone application was reported in [26]. Most of the abovementioned instruments used a system where the complete platform has a short shelf life. In addition, the devices had a complex readout system, mainly based on an optical principle, an application that is not justified in some circumstances (for example, for visually impaired people).

It is evident that, despite some techniques providing promising results, there is still a growing need for rapid, cost-efficient, and reliable systems for anticancer drug detec- tion. For example, a paper-based electrochemical cytodevice for sensitive detection of in situ anticancer drug screening was presented in [27] and carbon-based ruthenium nanomaterial-based electroanalytical sensors for the detection of anticancer drug idarubicin [28]. Both studies presented a design of sensitive sensors for anticancer drug detection. However, in the mentioned studies and similar previous work, there is a lack of detailed analysis and description of the sensing mechanism.

Advancing the state of the art, in research presented in this paper, we are not limited just to the development of a platform for expedited detection of anticancer drug type and concentrations. Multiwalled carbon nanotubes (MWCNTs) were deposited on top of the disposable paper strip. When the strip was inserted into the platform, a conductive path between the two copper foils was established, closing the gap between them. The fluid placed on top of the paper strip can be detected by measuring the resistance at the end of the thin copper foil. Such an approach is a simple, cost-effective technique for the rapid detection of different fluids (approximately 1 minute is required). Additionally, we used electrical impedance spectroscopy to obtain impedance data during the change of the anticancer drug type (methotrexate and cyclophosphamide) and concentration of $7.18 \mu \mathrm{mol} / \mathrm{mL}$ and $125 \mu \mathrm{mol} / \mathrm{mL}$ of methotrexate with the aim of proposing equivalent electrical circuit. Elements of the proposed electrical circuit correspond to physical processes and medium changes when the anticancer drugs are presented in the microfluidic channel. With parameter estimation of equivalent circuit elements, we showed that our system can distinguish the same concentration of two different drugs (methotrexate and cyclophosphamide). Moreover, a proofof-concept readout portable electronic system was developed for processing and displaying the measured results providing the complete solution for in situ anticancer drug detection.

\section{Experimental}

2.1. Fabrication of Tested Materials and Card Overall Structure. The test card was composed of five layers as illustrated in Figure 1(a). The bottom substrate layer was prepared from Polyvinyl Chloride (PVC) foil, transparent and physically flexible, with dimensions of $7.5 \mathrm{~cm} \times 4 \mathrm{~cm}$. This plastic laminating foil had a thickness of $80 \mu \mathrm{m}$. On this layer, two thin copper foils were placed. The length of each copper electrode was $3.5 \mathrm{~cm}$, the width was $8 \mathrm{~mm}$, and the gap between them was $5 \mathrm{~mm}$. Above this, three PVC foil layers were situated, featuring a central channel where the paper test strip was to be inserted. The thickness of the three layers was adjusted to suit the insertion of the paper test strip. The channel was $1 \mathrm{~cm}$ wide, so the ends of each electrode entered the channel by $1 \mathrm{~mm}$. The final top layer was again transparent PVC foil and contained terminals from the copper foils for electrical connection. This top layer of foil has also a role to protect the complete structure from unwanted environmental conditions, such as humidity. The overall dimensions of the test card are presented in Figure 1(b). The total dimensions chosen for the platform were similar to familiar 


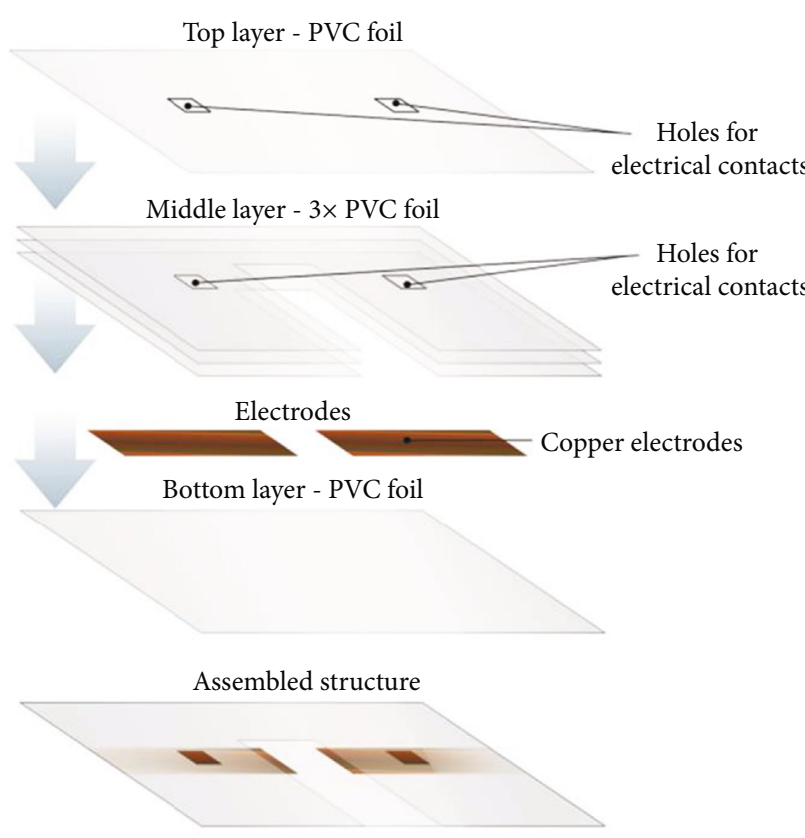

(a)

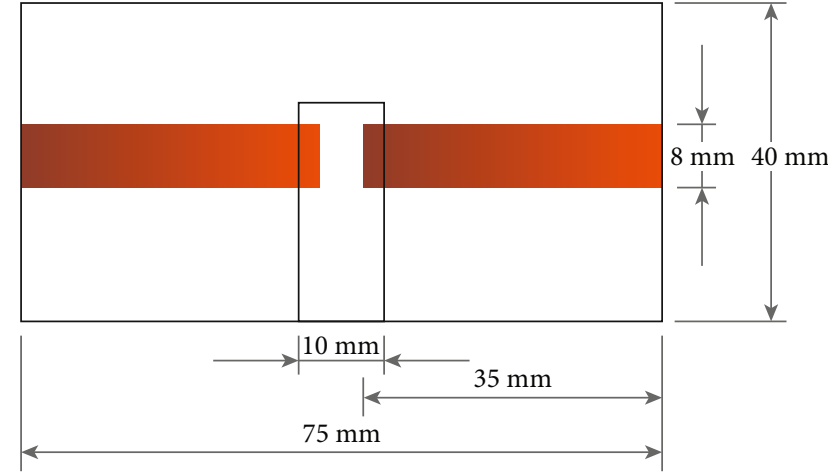

(b)

Figure 1: (a) Layers of the test card; (b) layout of the test card.

cards such as bank, parking, and USB cards for handling convenience.

Fabrication of the test card was done using a xurography technique (by means of a cutting plotter Graphtec ce6000-60 machine, Graphtec America Inc., USA). The five layers depicted in Figure 1(a) were laminated using a Card Laminator device set at a temperature of $150^{\circ} \mathrm{C}$ to provide a compact platform. The fabricated component is shown in Figure 2(a), and its cross-section is depicted in Figure 2(b), where the opening for inserting the paper test strip is visible. For testing purposes, the layer of MWCNTs was deposited on top of the test paper.

\subsection{Fabrication of Tested Materials and Card Overall} Structure. Two types of paper from the company Felix Schoeller Group (Felix Schoeller Group, Germany) [29] were used for the creation of the test paper strips. One type of paper, labelled Paper 2, had a thickness of $210 \mu \mathrm{m}$. The other one, labelled Paper 3, had a thickness of $150 \mu \mathrm{m}$. These papers are compatible with printed electronic fabrication methods, such as inkjet printing. A piece of paper $1 \mathrm{~cm}$ wide and $3 \mathrm{~cm}$ long was created to be inserted into the channel between the copper electrodes (Figure 2(a)). Due to the given width of the piece of paper, there is an overlap with the copper electrodes to establish a conductive path. For better conductivity, a layer of conductive MWCNT material was applied to the top of the paper, as can be seen in Figure 3(a).

2.3. Fabrication of Tested Materials and Card Overall Structure. MWCNT synthesis was carried out for $1 \mathrm{~h}$ in a flow of ethylene/nitrogen mixture $(1: 1)$ at $700^{\circ} \mathrm{C}$, using an in situ prereduced $5 \% \mathrm{Fe}-\mathrm{Co} / \mathrm{Al}_{2} \mathrm{O}_{3}$ catalyst. The obtained raw

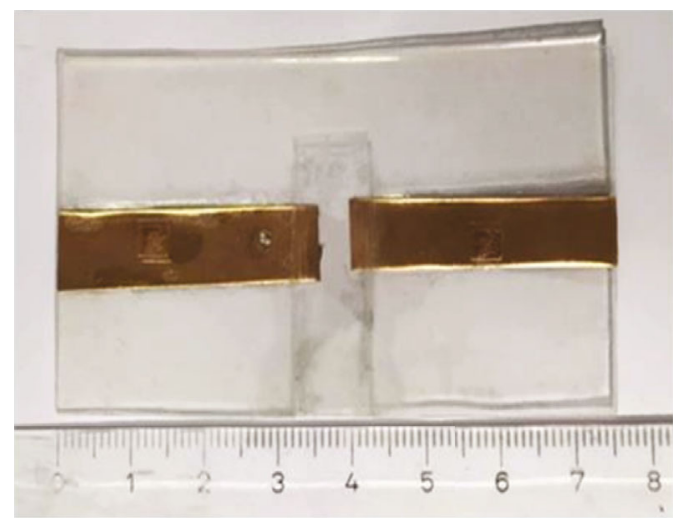

(a)

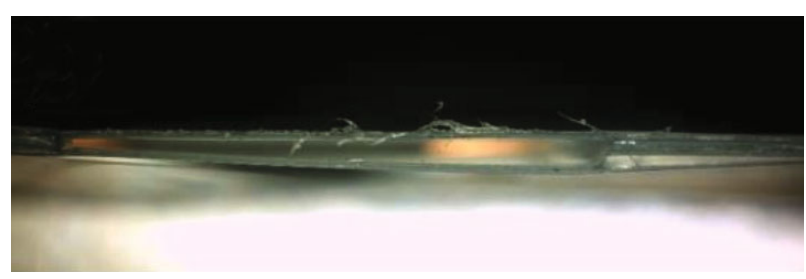

(b)

Figure 2: (a) Fabricated test card; (b) cross-section of the platform revealing the test strip insertion opening.

material was boiled under reflux for $6 \mathrm{~h}$ in diluted $\mathrm{NaOH}$ and $16 \mathrm{~h}$ in concentrated $\mathrm{HNO}_{3}$. The resultant sample was collected on a filter and rinsed with distilled water until the $\mathrm{pH}$ was neutralised, followed by drying at $110^{\circ} \mathrm{C}$ for $24 \mathrm{~h}$. The obtained functionalized nanotubes $(100 \mathrm{mg})$ were dispersed in 2-propanol, and polyvinylpyrrolidone (PVP) was 


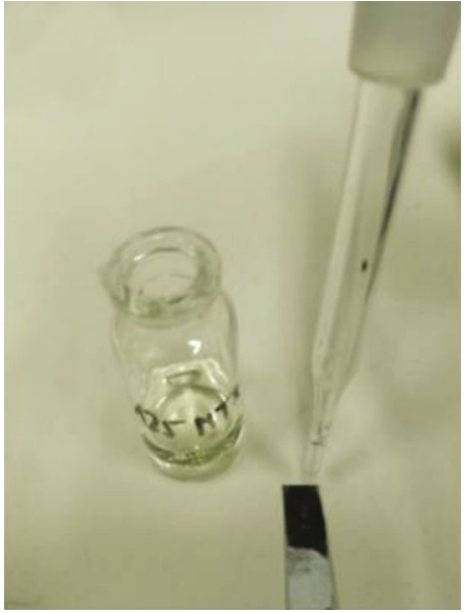

(a)

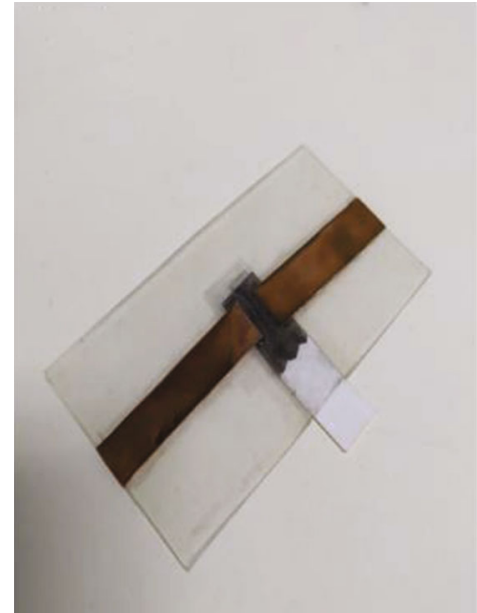

(b)

Figure 3: (a) Application of one drop of the drug to a paper strip; (b) the complete test card with inserted paper strip.

added to avoid agglomeration of MWCNTs. The dispersion of MWCNTs was prepared by ultrasonication treatment for $15 \mathrm{~min}$ at $5^{\circ} \mathrm{C}$. The MWCNT dispersion was deposited on the two paper substrates. Figure 3(b) depicts inserting this paper strip into the channel in the card platform.

2.4. Testing Unique Properties of Fluids. The fabricated platform with a strip paper tester was used for the detection of different concentrations of the cytostatic drug methotrexate (MTX). The drug concentrations used for calibration were $7.18 \mu \mathrm{mol} / \mathrm{mL}$ and $125 \mu \mathrm{mol} / \mathrm{mL}$ of MTX. These concentrations were selected because this range was realistic in the application during chemotherapeutic procedures. Each drug solution was prepared with LCMS Grade Water (Fisher Scientific, USA) as a solvent and tested at pH 7.0 and temperature of $20^{\circ} \mathrm{C}$. The solvent LCMS Grade Water was used because it is submicron filtered and contains exceptionally low metal concentrations and very low ultraviolet absorbance values. One drop of the given drug concentration was applied on the paper test strip in the area where the conductive MWCNT material was deposited. One minute after the fluid sample was applied, the measurements were conducted.

2.5. Characterization Methods. The two copper electrodes were constructed so that they have two access points, which enabled the connection of the microfluidic platform with the Chemical Impedance Analyzer (Hioki IM3590, Hioki E.E. Corporation, Japan). We measured the real (electrical resistance) and the imaginary part (electrical admittance) of impedance, in the frequency range from $20 \mathrm{~Hz}$ to $200 \mathrm{kHz}$, for different sample concentrations. We chose electrical impedance measurements as a noninvasive characterization method to obtain data which can be easily used for parameter estimation of equivalent electrical circuit elements. Such an approach enables better understanding of the sensing mechanism as well as development of portable economical devices for in situ measurements outside the laboratory.

\section{Results and Discussion}

3.1. Electrical Impedance Measurements. Figure 4 shows the measured electrical resistance $\left(Z^{\prime}(\Omega)\right.$, real part of complex impedance) of the test card as a function of frequency for two types of paper strips, each with a deposited layer of MWCNTs. It can be concluded from Figure 4 that a higher concentration of MTX in the fluid leads to higher resistance at the copper wire terminals. This is a consequence of an increase in the specific electrical resistance with an increase in MTX concentration [30]. The structure created using Paper 3 has slightly higher electrical resistance, which might be attributed to the lower contact angle of Paper 3 compared to Paper 2. Specifically, as it was reported earlier in [31], Paper 3 has a contact angle of around 24 degrees, compared to approximately 60 degrees for Paper 2 . As a consequence, a drop of MTX deposited on the paper substrate will be more consistent and durable on the surface of Paper 2, contributing to the lower resistance between the copper foils in comparison with the Paper 3 strip.

Calibration curves using the solutions with two test concentrations for Paper 2 and Paper 3 at $20 \mathrm{~Hz}$ and $200 \mathrm{kHz}$ are given with equations (1)-(4):

Paper $2(20 \mathrm{~Hz})$ :

$$
Y=2.924 \cdot X+234.9
$$

Paper $2(200 \mathrm{kHz})$ :

$$
Y=2.419 \cdot X+178.4
$$

Paper $3(20 \mathrm{~Hz})$ :

$$
Y=2.182 \cdot X+340.1
$$

Paper $3(200 \mathrm{kHz})$ :

$$
Y=2.264 \cdot X+253.1
$$




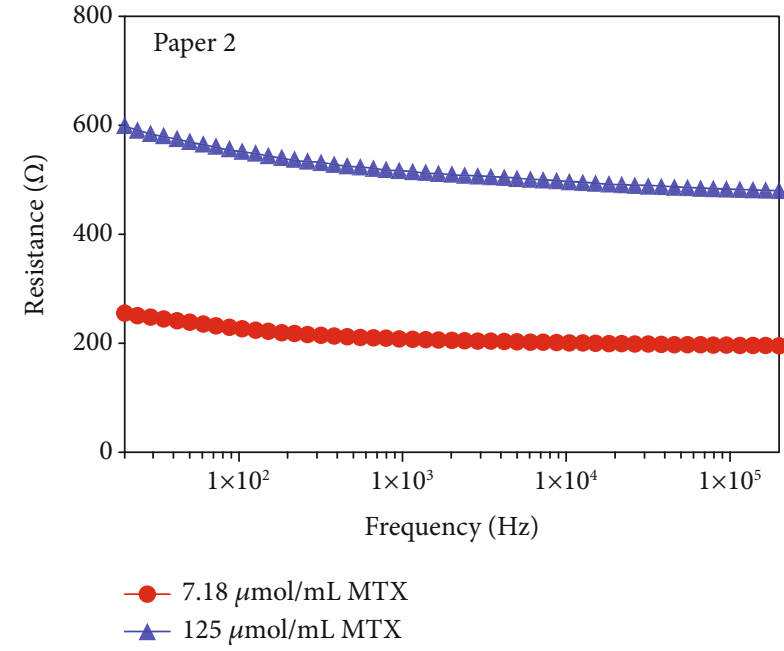

(a)

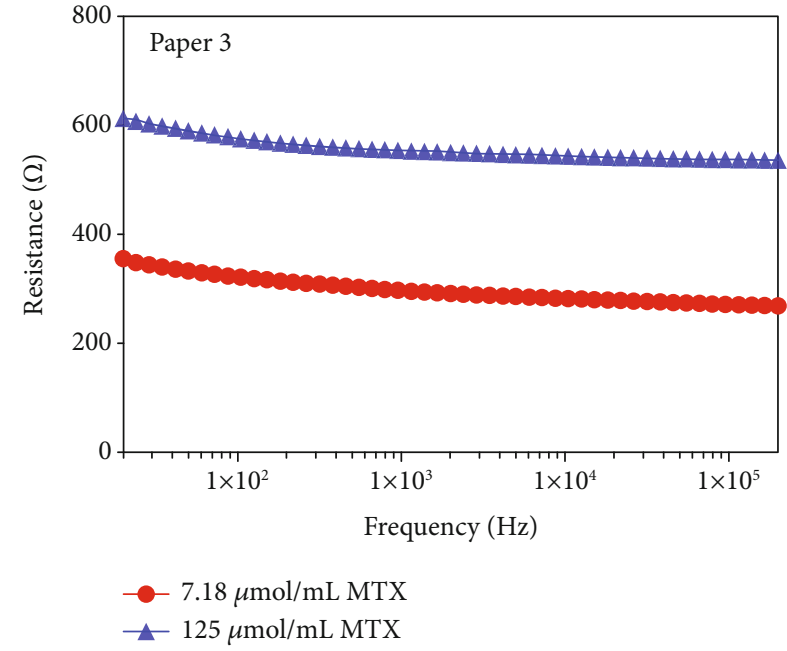

(b)

Figure 4: (a) Resistance as a function of frequency for $7.18 \mu \mathrm{mol} / \mathrm{mL}$ and $125 \mu \mathrm{mol} / \mathrm{mL}$ of MTX for Paper 2; (b) resistance as a function of frequency for $7.18 \mu \mathrm{mol} / \mathrm{mL}$ and $125 \mu \mathrm{mol} / \mathrm{mL}$ of MTX for Paper 3 .

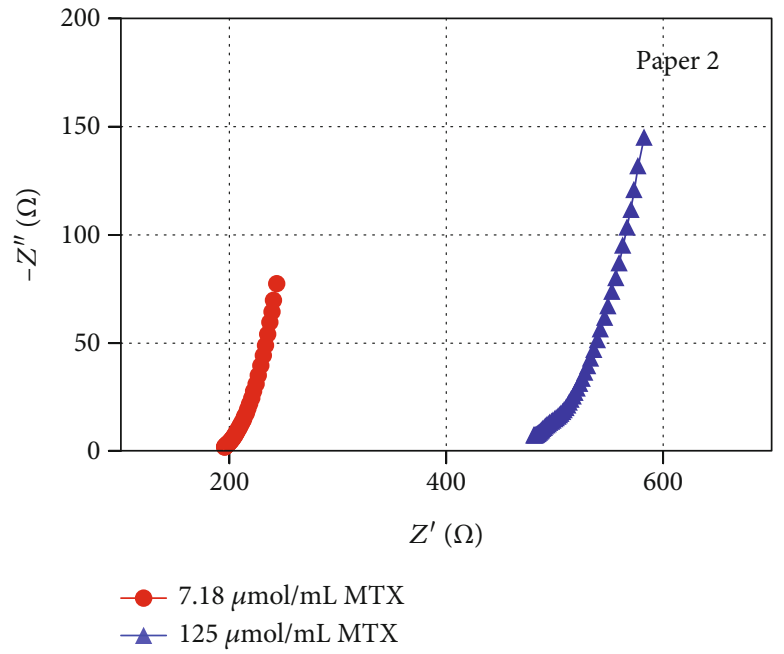

(a)

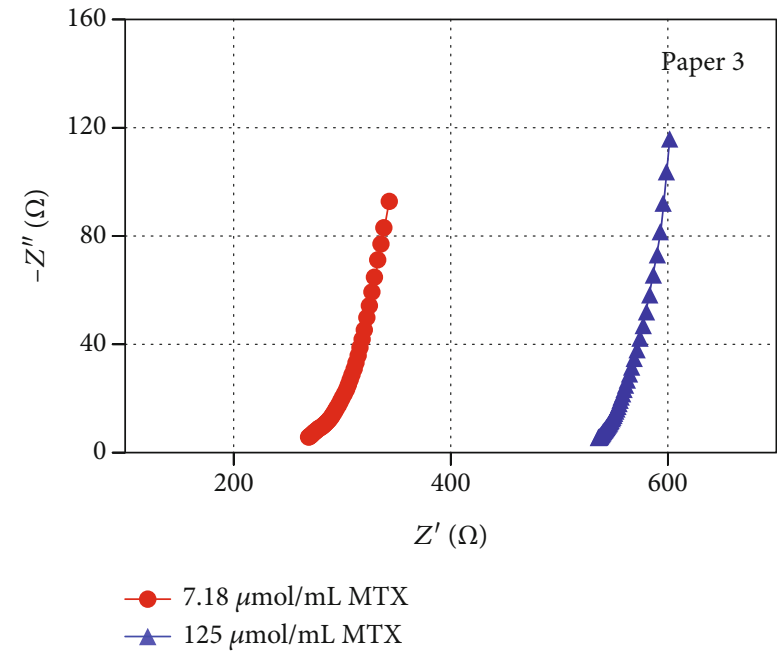

(b)

Figure 5: Nyquist plot for the platform based on (a) Paper 2 and (b) Paper 3.

where $Y$ is electrical resistance of the sensor and $X$ is MTX concentration.

A Nyquist plot shows the change of resistance $\left(Z^{\prime}\right.$ $(\Omega))$ versus negative signed reactance $\left(-Z^{\prime \prime}(\Omega)\right)$ over the analyzed frequency range. Nyquist plots are a very useful method for understanding sensing mechanisms. Figure 5 depicts the Nyquist plots for these two papers, providing a clear distinction between the applied concentrations of MTX.

Since this study is a continuation and extension of earlier research on methotrexate in pediatric malignant blood disorders, we have chosen another drug that is frequently used in the treatment of this type of disease in children. Therefore, in order to demonstrate that the proposed platform can detect different anticancer drugs at the same concentration, we applied $125 \mu \mathrm{mol} / \mathrm{mL}$ MTX and the same concentration of cyclophosphamide (CIK), and the results are presented in Figure 6. Both medications, MTX and CIK, are used in chemotherapy to treat cancer $[32,33]$. Although it is well known that factors such as temperature, $\mathrm{pH}$, and solvent constituents can influence the conductivity of electrolytic solutions, specific molecular characteristics of MTX and CIK are likely to contribute to the differences in conductivity in this instance. For example, the greater number of hydrogen bond donor (5) and acceptor (12) sites of MTX [34] is likely to increase the number of $\mathrm{H}^{+}$ions and thus its conductivity in solution, compared to that of CIK, which contains only 1 and 4 donor and acceptor sites, respectively [35]. 


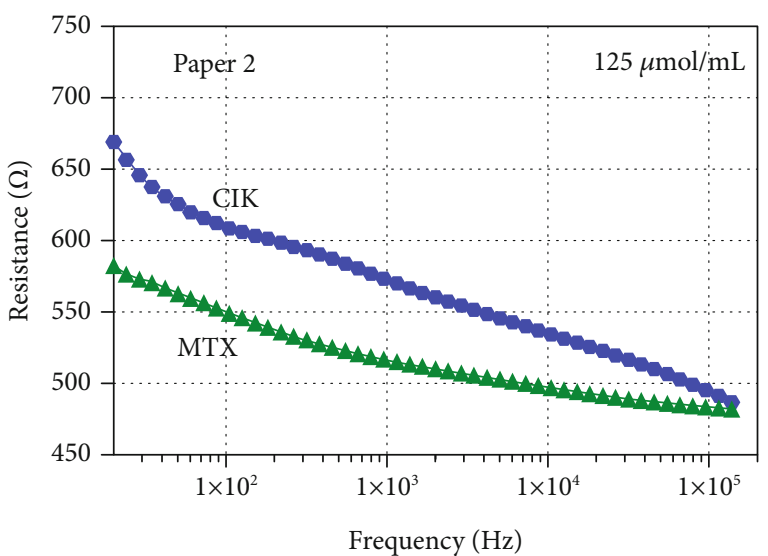

(a)

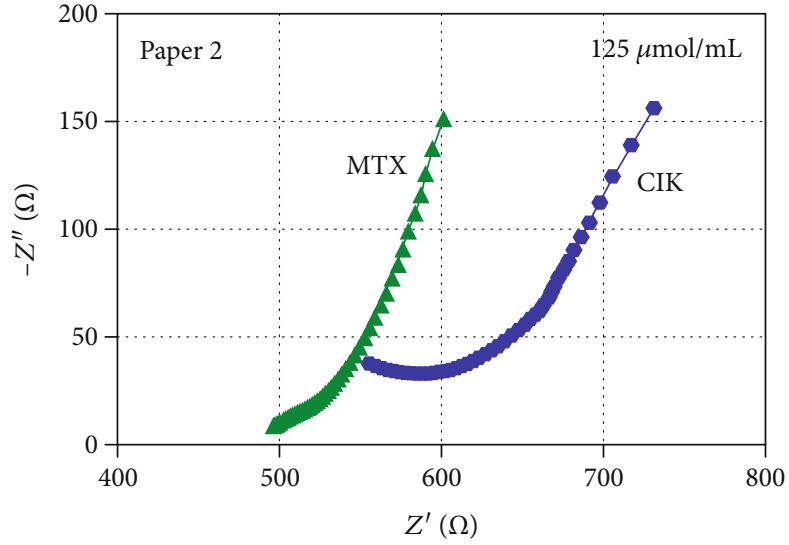

(b)

Figure 6: (a) Resistance as a function of frequency; (b) Nyquist plot, for $125 \mu \mathrm{mol} / \mathrm{mL}$ of MTX and CIK, for Paper 2.

As can be seen from Figure 6, sensor resistances decrease as frequency increases for both anticancer drugs. Even overall resistance is higher in the case of CIK; there is a need for a better understanding of the sensing mechanism and higher reliability for anticancer drug type/concentration detection. Our approach is to propose equivalent electrical circuit composed of elements representing the structure and physical process on the surface of the sensor when an anticancer drug is applied. Then, model parameters are estimated from the measurements during the calibration (applied anticancer drug type and concentration are known). During that process, the specific pattern of model parameter changes is obtained. In later use, the system is able to recognize anticancer drug type/concentration if that pattern of parameters is estimated. Such an approach requires calibration with specific anticancer drug types and concentrations, but it offers a high level of identification. Equivalent electrical circuit and sensing mechanism are described in Subsection 3.2.

3.2. Equivalent Electrical Circuit and Sensing Mechanism. It is clear from figures in the previous subsection that a drop of MTX and/or CIK on our sensor results in a very similar response to that of the series RC circuit. In such representation, resistance $R$ is the resistance of the solution due to the current pathway through the electrolyte. Capacitor $C$ represents a double-layer structure formed between electrodes and electrolyte. However, many analyses showed that a simple RC circuit is not suitable to fit experimental data, mostly due to the nonhomogeneous porosity. Therefore, a capacitor is replaced by a constant phase element (CPE), forming the circuit shown in Figure 7(a). A CPE represents a frequencydependent capacitor with two frequency-independent parameters: double-layer capacitance $C$ and a nondimensional parameter, $\alpha$ (takes values between 0 and 1). Parameter $\alpha$ represents an exponent tuning the nonideality. As an illustrative example, a Nyquist plot of such a circuit $(R=100 \Omega, C=$ $0.01 \mathrm{mF}$, and $\alpha=0.687)$ for the frequency range $20 \mathrm{~Hz}-$ $200 \mathrm{kHz}$ is shown in Figure 7(b).

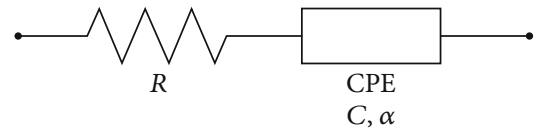

(a)

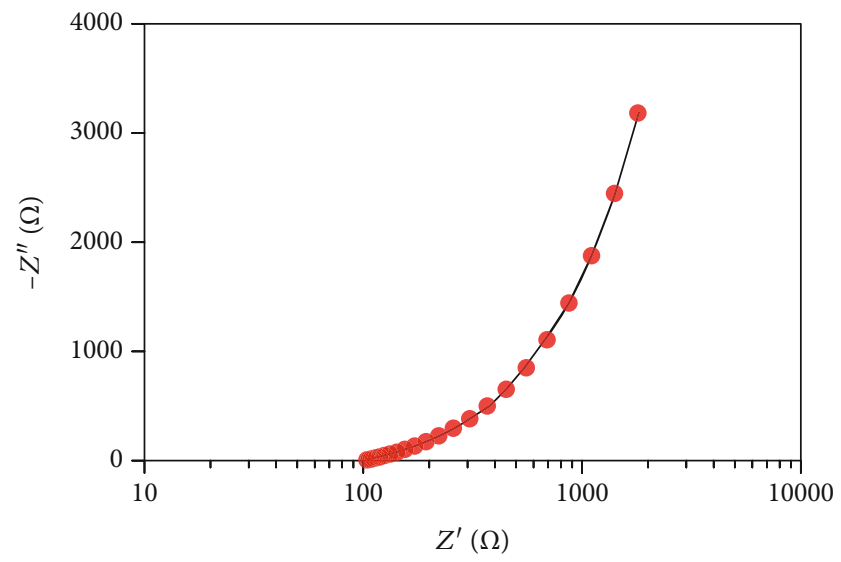

(b)

Figure 7: (a) Proposed equivalent electrical circuit. (b) Typical Nyquist plot of the proposed equivalent electrical circuit.

Complex impedance of the circuit shown in Figure 7(a) is given with equation (1):

$\underline{Z}=Z^{\prime}+j Z^{\prime \prime}=R+\frac{1}{C(j \omega)^{\alpha}}=R+\frac{\cos (\alpha \pi / 2)}{C(\omega)^{\alpha}}-j \frac{\sin (\alpha \pi / 2)}{C(\omega)^{\alpha}}$.

We used MEISP software to fit the measured data. Estimated values of model parameters for different concentrations of MTX are shown in Tables 1 and 2.

As already discussed, the MTX solution becomes less conductive with increased concentration, making it reasonable to expect increased $R$. To anticipate the expected values of $C$, it is necessary to be mindful that the dielectric constant 
TABLE 1: Paper 2: estimated values of model parameters for different concentrations of MTX.

\begin{tabular}{lccc}
\hline MTX concentration & $R(\Omega)$ & $C(\mathrm{mF})$ & $\alpha$ \\
\hline $7.18 \mu \mathrm{mol} / \mathrm{mL}$ & 194.30 & 0.577 & 0.548 \\
$125 \mu \mathrm{mol} / \mathrm{mL}$ & 485.76 & 0.519 & 0.493 \\
\hline
\end{tabular}

TABLE 2: Paper 3: estimated values of model parameters for different concentrations of MTX.

\begin{tabular}{lccc}
\hline MTX concentration & $R(\Omega)$ & $C(\mathrm{mF})$ & $\alpha$ \\
\hline $7.18 \mu \mathrm{mol} / \mathrm{mL}$ & 274.55 & 0.840 & 0.466 \\
$125 \mu \mathrm{mol} / \mathrm{mL}$ & 520.71 & 0.756 & 0.419 \\
\hline
\end{tabular}

is inversely proportional to the electric field (actually it is a ratio of polarization density and electric field). Therefore, the electric field is lower (higher dielectric constant) if the material is a better conductor (electrical field is zero inside the ideal conductor). As the material becomes less conductive, it is expected that $C$ will decrease. Values obtained for $R$ and $C$ in Tables 1 and 2 support this analysis. It should be noted that the actual size of the sensor can affect absolute values of $R$ and $C$, but it is reasonable to expect that those parameters will have the same trend of the change and relative ratio as obtained in the presented study.

The anticipated changes in $R$ and $C$ values, as discussed above, can assist in determining the comparative effectiveness of the two paper strips. As mentioned earlier, Paper 3 had lower contact angle values than Paper 2, giving rise to comparatively higher values for $R$. Therefore, Paper 2 provided the required characteristics for the proposed sensing mechanism: increasing concentrations of MTX lead to an increase of solution resistance $R$ and a decrease of both double-layer capacitance $C$ and nondimensional parameter $\alpha$.

In addition, increasing the concentration of CIK from $7.18 \mu \mathrm{mol} / \mathrm{mL}$ to $125 \mu \mathrm{mol} / \mathrm{mL}$ in the case of Paper 3 leads to an increase of solution resistance $R$ and decrease of double-layer capacitance $C$ and nondimensional parameter $\alpha$.

Additionally, we have analyzed the quality of the proposed electrical circuit with relative error calculations between measured values of resistance $\left(R_{\text {meas }}\right)$ and values calculated using estimated values of model parameters $\left(R_{\text {est }}\right)$ :

$$
\Delta_{R}=100 \frac{R_{\text {est }}-R_{\text {meas }}}{R_{\text {meas }}}(\%) \text {. }
$$

The obtained results (Figure 8) indicate that the proposed equivalent circuit estimates values within 3\% relative error in the frequency range $50 \mathrm{~Hz}-200 \mathrm{kHz}$ for Paper 2 and Paper 3.

As mentioned above, we have compared the sensor response to the same concentration $(125 \mu \mathrm{mol} / \mathrm{mL})$ of two different drugs (MTX and CIK). Estimated values generated using MEISP software are given in Table 3. As can be seen, values of $R$ and $C$ are higher while $\alpha$ is lower for CIK, which enables differentiation between these two drugs.

The quality of the proposed model for CIK recognition was analyzed with relative error calculations. Obtained values for CIK in the frequency range $60 \mathrm{~Hz}-5 \mathrm{kHz}$ are shown in Figure 9. As can be seen, in the selected frequency range, relative errors are in the range of 3\% (relative errors for MTX are already shown in Figure 8).

3.3. Analytical Application. As a part of the validation process of the proposed platform, we have performed impedance measurement at $62.5 \mu \mathrm{mol} / \mathrm{mL}$ of MTX. Obtained results are shown in Figure 10.

By inserting measured values of resistance in equations (1)-(4), we have compared relative errors of the expected value of resistance that will provide the concentration of $62.5 \mu \mathrm{mol} / \mathrm{mL}$ and measured resistance at the same concentration. Obtained values are summarized in Tables 4 and 5 .

As it can be seen, Paper 3 provides a considerably smaller relative error at both test frequencies.

Additionally, we have estimated parameters of equivalent electrical circuit with measured impedance $62.5 \mu \mathrm{mol} / \mathrm{mL}$ MTX, as shown in Table 6.

As it can be seen, estimated values for model parameters are between values for $7.18 \mu \mathrm{mol} / \mathrm{mL}$ and $125 \mu \mathrm{mol} / \mathrm{mL}$ (shown in Tables 1 and 2). Moreover, estimated values have the same relationship: $R$ and $C$ are higher for Paper 3, while $\alpha$ is lower.

3.4. Readout Electronic Circuit. An advantage of our sensor is reliability, insofar that analysis of the tested fluids compares favorably with the equivalent electrical circuit, providing an explanation of the sensing mechanism for drug detection and distinction. In general, if sensor behavior is well understood in the characterization process, then some simpler procedure can be implemented for in situ measurements. Measurements outside the laboratory require an appropriate and reliable portable impedance measurement device. The platform can be used many times, and the paper strip was designed to be a disposable part for in situ measurements, but from our laboratory experimental setup, we concluded that even this strip can be used more than 10 times without degradation of performances.

We have already developed a battery-powered complex impedance measurement system, applied in interfaces with $\mathrm{pH}$ [36] and bacteria [37] sensors. Our device consists of a block for the generation of the reference AC voltage (which will cause a flow of electrical current through the sensor) and processing of the voltage across the sensor with discrete Fourier transformation. Overall, error of the developed device is lower than $3 \%$ in measurements of impedance magnitude and lower than $2^{\circ}$ for the phase angle [38]. The system includes a thin film transistor (TFT) display, an embedded keypad, and SD card for local data storage. Moreover, dimensions of the device $(7.7 \mathrm{~cm} \times 7.5 \mathrm{~cm})$ are suitable for portable applications. The hardware of the measurement system connected with the developed microfluidic platform is shown in Figure 11.

A polynomial transfer function can be used to efficiently determine which drug is presented and at what concentration, using the measured resistance at some frequency. As demonstrated, using values obtained for all three concentrations of $\operatorname{MTX}(7.18,62.5$, and $125 \mu \mathrm{mol} / \mathrm{mL})$, we have 


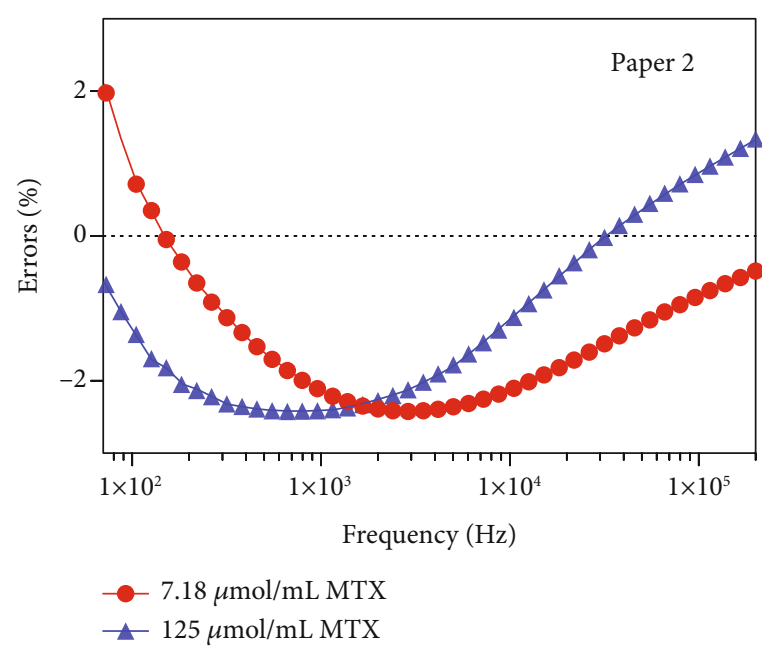

(a)

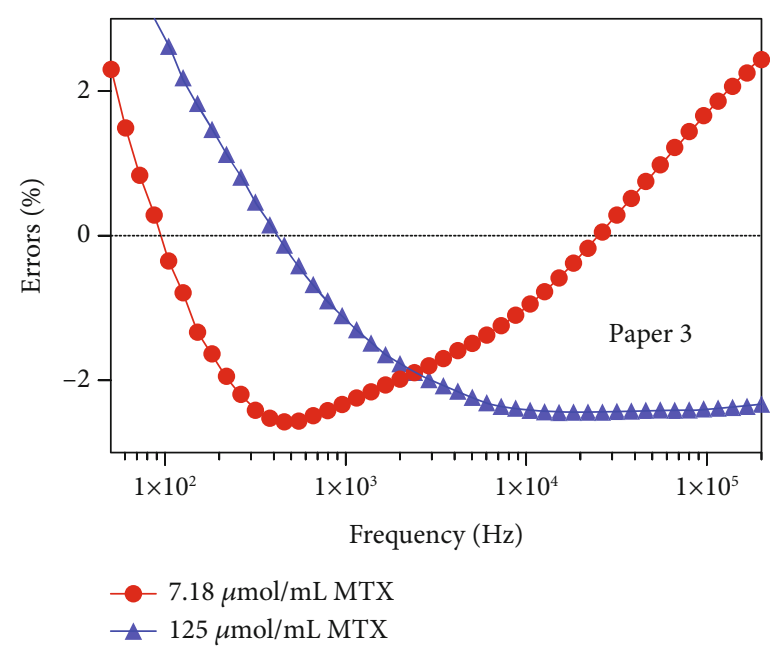

(b)

Figure 8: (a) Relative errors between measured and estimated values of impedance for (a) Paper 2 and (b) Paper 3.

TABLE 3: Estimated values of model parameters of the sensor (paper 2) for the same concentration of MTX and CIK.

\begin{tabular}{lccc}
\hline Drug concentration & $R(\Omega)$ & $C(\mathrm{mF})$ & $\alpha$ \\
\hline $125 \mu \mathrm{mol} / \mathrm{mL} \mathrm{CIK}$ & 587.687 & 0.581 & 0.420 \\
$125 \mu \mathrm{mol} / \mathrm{mL} \mathrm{MTX}$ & 485.76 & 0.519 & 0.493 \\
\hline
\end{tabular}

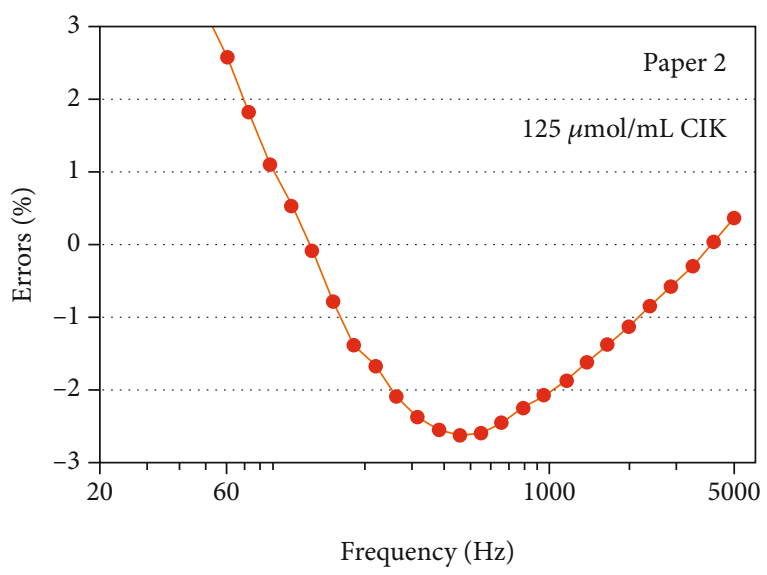

FIGURE 9: Relative errors between measured and estimated values for Paper 2 when $125 \mu \mathrm{mol} / \mathrm{mL}$ CIK was applied.

performed polynomial fitting for Paper 2. As there are three concentrations of MTX, measurement values of resistance $\left(Z^{\prime}\right)$ at some frequency $(f)$ are fitted with a second-order polynomial:

$$
\text { Estimated concentration }=p_{1}\left(Z^{\prime}\right)^{2}+p_{2} Z^{\prime}+p_{3}
$$

For example, polynomial coefficients obtained using values for Paper 2 at a frequency of $2 \mathrm{kHz}$ (more decimal places are kept to maintain accuracy) are $p_{1}=556.806758593210 \times 10^{-6}$ $\mu \mathrm{mol} /\left(\mathrm{mL} \Omega^{2}\right), \quad p_{2}=14.0276208460598 \times 10^{-3} \mu \mathrm{mol} /(\mathrm{mL} \Omega)$, and $p_{3}=-35.9565293128714 \mu \mathrm{mol} /(\mathrm{mL})$. Polynomial coeffi- cients and measurement data $\left(Z^{\prime}\right)$ were then placed in equation (7) to calculate the concentration at nearby frequencies, as shown in Table 7.

As can be seen from Table 7, estimated concentrations are very close to the reference values.

The analytical application of the presented platform can be for the quantification of anticancer drug concentration in fluids. Our study demonstrated that the sensor can be successfully used for selective determination of MTX and CIK in solution. The quantitative analysis was based on the detection of the differences in electrical resistance of the sample which then correlates with the drug concentration. The presented device provides a useful tool for solving the actual problem of the pharmaceutical sciences, namely, sensitive detection of some types of fluids and drugs, and can be interesting to the specialists working in this field. The procedure can also be adopted for quality control laboratory studies.

One potential application of our system might be therapeutic drug monitoring in patients with acute lymphoblastic leukemia treated with methotrexate. This drug is characterized by dose-dependent side effects. The administration of antidote leucovorin is thought to decrease the toxic side effects of methotrexate. The decision on starting leucovorin rescue therapy is based on methotrexate blood concentration. One of the widely used techniques in measuring the methotrexate blood level is ELISA which requires specific antibodies and relatively long analytical time, together with expensive instrumentation, expensive consumables, and trained personnel. In this situation, paper-based microfluidic devices represent a practical alternative for testing with advantages of easy fabrication, simple operation (can be used by untrained staff), rapid production of results, and cost-effectiveness.

\section{Conclusions}

We have developed a safe, low-cost, portable, and robust platform for biosensing applications that should prove particularly useful for decentralized analysis in biomedicine. Concretely, in this manuscript, we used the solution with 


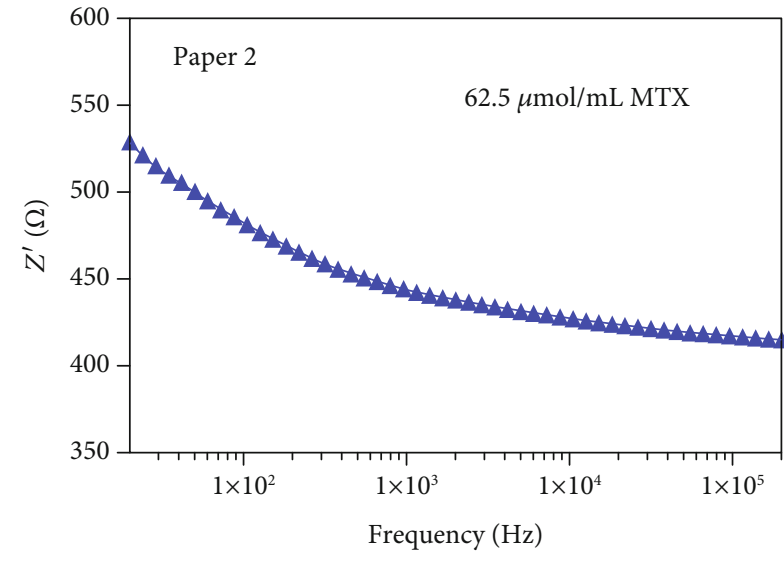

(a)

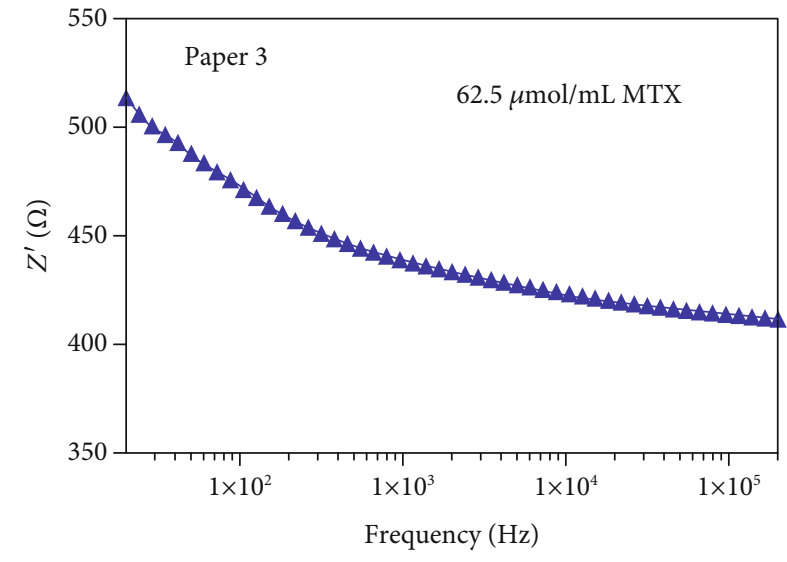

(b)

FIGURE 10: (a) Resistance as a function of frequency for $62.5 \mu \mathrm{mol} / \mathrm{mL}$ of MTX for Paper 2. (b) Resistance as a function of frequency for $62.5 \mu \mathrm{mol} / \mathrm{mL}$ of MTX for Paper 3 .

TABLE 4: Comparison of expected and measured values of sensor resistance at $20 \mathrm{~Hz}$ and $200 \mathrm{kHz}$ for Paper 2 .

\begin{tabular}{lccc}
\hline Frequency & $\begin{array}{c}\text { Expected values of } Z^{\prime} \\
(\Omega)\end{array}$ & $\begin{array}{c}\text { Measured value of } Z^{\prime} \\
(\Omega)\end{array}$ & $\begin{array}{c}\text { Error } \\
(\%)\end{array}$ \\
\hline $20 \mathrm{~Hz}$ & 398.90 & 529.11 & -24.61 \\
$200 \mathrm{kHz}$ & 329.59 & 415.1872 & -20.61 \\
\hline
\end{tabular}

TABle 5: Comparison of expected and measured values of sensor resistance at $20 \mathrm{~Hz}$ and $200 \mathrm{kHz}$ for Paper 3 .

\begin{tabular}{lccc}
\hline Frequency & $\begin{array}{c}\text { Expected values of } Z^{\prime} \\
(\Omega)\end{array}$ & $\begin{array}{c}\text { Measured value of } Z^{\prime} \\
(\Omega)\end{array}$ & $\begin{array}{c}\text { Error } \\
(\%)\end{array}$ \\
\hline $20 \mathrm{~Hz}$ & 476.48 & 513.78 & -7.26 \\
$200 \mathrm{kHz}$ & 394.60 & 411.70 & -4.15 \\
\hline
\end{tabular}

TABle 6: Estimated values of model parameters of the sensors (Paper 2 and Paper 3) for the concentration $62.5 \mu \mathrm{mol} / \mathrm{mL}$ MTX.

\begin{tabular}{lccc}
\hline Paper type & $R(\Omega)$ & $C(\mathrm{mF})$ & $\alpha$ \\
\hline Paper 2 & 411.23 & 0.520 & 0.530 \\
Paper 3 & 415.44 & 0.798 & 0.455 \\
\hline
\end{tabular}

the known/defined concentration of anticancer drugs, and we presented a new method and platform which is costeffective and fast.

The biosensor can be used without sample (e.g., for biological samples and drugs) pretreatment or specialized personnel, demonstrating the robustness of the proposed technique. It is comprised of a PVC test card featuring a replaceable paper strip functionalized with a layer of MWCNTs. When fluid is placed on top of the test paper strip, the conductivity of the MWCNTs changes. The fabricated paper strip is designed for one-time-use and is the only disposable part. The PVC card is reusable.

To demonstrate the functionality of this platform, we have detected different concentrations of the cytostatic drug

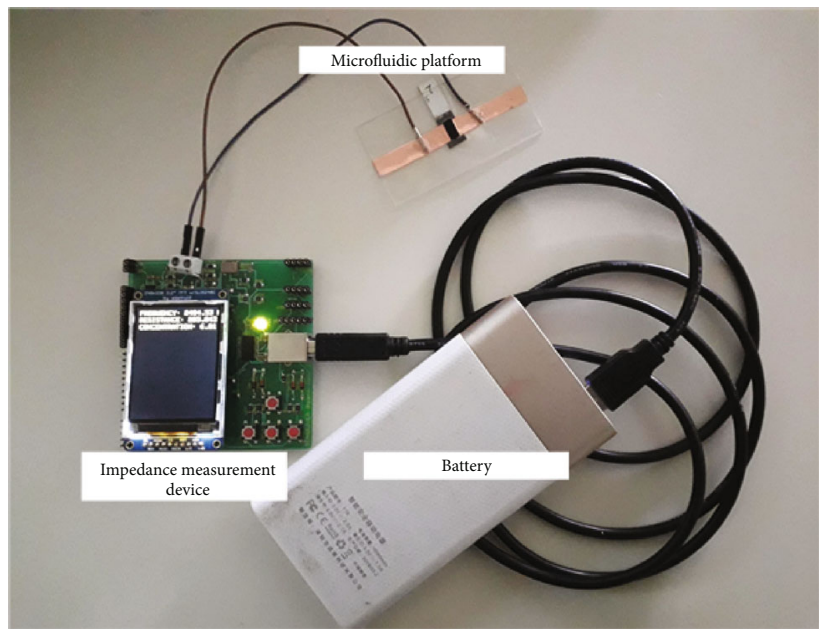

FIgURE 11: The hardware of the portable system for rapid detection of anticancer drug concentration.

TABLE 7: Comparison of reference and estimated values of MTX concentrations in $\mu \mathrm{mol} / \mathrm{mL}$.

\begin{tabular}{lccc}
\hline & $7.18 \mu \mathrm{mol} / \mathrm{mL}$ & $\begin{array}{c}\text { Reference values } \\
62.5 \mu \mathrm{mol} / \mathrm{mL}\end{array}$ & $125 \mu \mathrm{mol} / \mathrm{mL}$ \\
\hline$f(\mathrm{~Hz})$ & & Estimated values \\
796.21 & 9.47 & 65.77 & 127.81 \\
957.26 & 8.94 & 65.03 & 127.17 \\
1150.88 & 8.44 & 64.36 & 126.60 \\
1383.66 & 7.99 & 63.71 & 126.08 \\
1663.53 & 7.56 & 63.09 & 125.56 \\
2404.53 & 6.81 & 61.93 & 124.49 \\
2890.88 & 6.46 & 61.38 & 124.00 \\
3475.60 & 6.14 & 60.83 & 123.50 \\
4178.59 & 5.83 & 60.30 & 123.04 \\
5023.77 & 5.54 & 59.79 & 122.65 \\
\hline
\end{tabular}


methotrexate and presented the data measured. The preliminary results and developed prototype are promising for application in numerous fluid analyses in biomedicine, although more work is required to assess the performance of the sensor in complex biological fluids. We have proposed an equivalent electrical circuit suitable for the representation of sensor behavior in the analyzed frequency range. Using estimated values of model parameters, it was possible to explain the sensing mechanism and to recognize the pattern of parameter changes due to the presence of MTX or CIK or different concentrations of MTX. As the preliminary results and developed prototype are promising for application in numerous fluid analyses in biomedicine, we concentrated on the development of a handheld impedance measurement device as well. The portability and small dimensions of the measurement device provide promising characteristics and the potential for integration with the presented sensors. Moreover, rapid on-site detection of the presence and concentration of biologically relevant substances such as anticancer drugs will be possible.

This study was a proof-of-concept study and will be followed by experiments with other anticancer drugs such are vincristine, cytarabine, daunorubicin, and doxorubicin. On the other hand, part of future experiments will also be to try to measure drug concentration in blood samples to test if the proposed platform can be used as a device in therapeutic drug monitoring.

\section{Data Availability}

Data is available on request.

\section{Conflicts of Interest}

The authors declare that they have no conflicts of interest.

\section{Acknowledgments}

This study has received funding from the European Union's Horizon 2020 research and innovation programme under the Marie Skłodowska-Curie grant agreement No. 872370 as well as being partially supported through the national project III45021.

\section{References}

[1] N. A. Meredith, C. Quinn, D. M. Cate, T. H. Reilly, J. Volckens, and C. S. Henry, "Paper-based analytical devices for environmental analysis," Analyst, vol. 141, no. 6, pp. 1874-1887, 2016.

[2] A. Nishat, A. T. Jafry, A. W. Martinez, and F. R. Awan, "Paperbased microfluidics: Simplified fabrication and assay methods," Sensors and Actuators B: Chemical, vol. 336, p. 129681, 2021.

[3] S. Sununta, P. Rattanarat, O. Chailapakul, and N. Praphairaksit, "Microfluidic paper-based analytical devices for determination of creatinine in urine samples," Analytical Sciences, vol. 34, no. 1, pp. 109-113, 2018.

[4] C. C. Tseng, R. J. Yang, W. J. Ju, and L. M. Fu, "Microfluidic paper-based platform for whole blood creatinine detection," Chemical Engineering Journal, vol. 348, pp. 117-124, 2018.
[5] W. Jung, J. Han, J. W. Choi, and C. H. Ahn, "Point-of-care testing (POCT) diagnostic systems using microfluidic lab-ona- chip technologies," Microelectronic Engineering, vol. 132, pp. 46-57, 2015.

[6] L. Guadarrama-Fernández, M. Novell, P. Blondeau, and F. J. Andrade, "A disposable, simple, fast and low-cost paperbased biosensor and its application to the determination of glucose in commercial orange juices," Food Chemistry, vol. 265, pp. 64-69, 2018.

[7] S. Rengaraj, Á. Cruz-Izquierdo, J. L. Scott, and M. di Lorenzo, "Impedimetric paper-based biosensor for the detection of bacterial contamination in water," Sensors and Actuators B: Chemical, vol. 265, pp. 50-58, 2018.

[8] K. Mahato, A. Srivastava, and P. Chandra, "Paper based diagnostics for personalized health care: emerging technologies and commercial aspects," Biosensors \& Bioelectronics, vol. 96, pp. 246-259, 2017.

[9] G. Ozcelikay, L. Karadurmus, S. I. Kaya, N. K. Bakirhan, and S. A. Ozkan, "A review: new trends in electrode systems for sensitive drug and biomolecule analysis," Critical Reviews in Analytical Chemistry, vol. 50, no. 3, pp. 212-225, 2020.

[10] M. T. Alula, L. Karamchand, N. R. Hendricks, and J. M. Blackburn, "Citrate-capped silver nanoparticles as a probe for sensitive and selective colorimetric and spectrophotometric sensing of creatinine in human urine," Analytica Chimica Acta, vol. 1007, pp. 40-49, 2018.

[11] Q. Wang, W. Li, D. Qian et al., "Paper-based analytical device for detection of extracellular hydrogen peroxide and its application to evaluate drug-induced apoptosis," Electrochimica Acta, vol. 204, pp. 128-135, 2016.

[12] Y. Zhang, P. Zuo, and B.-C. Ye, "A low-cost and simple paper-based microfluidic device for simultaneous multiplex determination of different types of chemical contaminants in food," Biosensors and Bioelectronics, vol. 68, pp. 14-19, 2015.

[13] S. H. Lee, J. H. Lee, V. K. Tran et al., "Determination of acetaminophen using functional paper-based electrochemical devices," Sensors and Actuators B: Chemical, vol. 232, pp. 514-522, 2016.

[14] W. Li, D. Qian, Y. Li, N. Bao, H. Gu, and C. Yu, "Fully-drawn pencil-on-paper sensors for electroanalysis of dopamine," Journal of Electroanalytical Chemistry, vol. 769, pp. 72-79, 2016.

[15] A. C. Glavan, D. C. Christodouleas, B. Mosadegh et al., "Folding analytical devices for electrochemical ELISA in hydrophobic RHpaper," Analytical Chemistry, vol. 86, no. 24, pp. 11999 12007, 2014.

[16] Z. Taleat, A. Khoshroo, and M. Mazloum-Ardakani, "Screenprinted electrodes for biosensing: a review (2008-2013)," Microchimica Acta, vol. 181, no. 9-10, pp. 865-891, 2014.

[17] L. Wang and B. McCord, "A four-channel paper microfluidic device with gold nanoparticles and aptamers for seized drugs," Analytical Biochemistry, vol. 595, p. 113619, 2020.

[18] R. Walczak, J. Dziuban, P. Szczepanska et al., "Toward portable instrumentation for quantitative cocaine detection with lab- on-a-paper and hybrid optical readout," Procedia Chemistry, vol. 1, no. 1, pp. 999-1002, 2009.

[19] T. I. B. Silva, F. T. C. Moreira, L. A. A. N. A. Truta, and M. G. F. Sales, "Novel optical PVC probes for on-site detection/determination of fluoroquinolones in a solid/liquid interface: application to the determination of norfloxacin in aquaculture 
water," Biosensors \& Bioelectronics, vol. 36, no. 1, pp. 199-206, 2012.

[20] H. I. A. S. Gomes and M. G. F. Sales, "Development of paperbased color test-strip for drug detection in aquatic environment: application to oxytetracycline," Biosensors \& Bioelectronics, vol. 65, pp. 54-61, 2015.

[21] O. Amor-Gutierrez, E. Costa Rama, A. Costa-Garcia, and M. T. Fernandez-Abedul, "Paper-based maskless enzymatic sensor for glucose determination combining ink and wire electrodes," Biosensors \& Bioelectronics, vol. 93, pp. 40-45, 2017.

[22] M. Guo, J. Wang, R. du et al., "A test strip platform based on a whole-cell microbial biosensor for simultaneous on-site detection of total inorganic mercury pollutants in cosmetics without the need for predigestion," Biosensors \& Bioelectronics, vol. 150, p. 111899, 2020.

[23] R. F. e Silva, T. R. Longo Cesar Paixão, M. der Torossian Torres, and W. R. de Araujo, "Simple and inexpensive electrochemical paper-based analytical device for sensitive detection of _Pseudomonas aeruginosa_,"Sensors and Actuators B: Chemical, vol. 308, p. 127669, 2020.

[24] X. Luo, J. Xia, X. Jiang, M. Yang, and S. Liu, "Cellulose-based strips designed based on a sensitive enzyme colorimetric assay for the low concentration of glucose detection," Analytical Chemistry, vol. 91, no. 24, pp. 15461-15468, 2019.

[25] J. Zinna, T. L. E. Lockwood, and M. Lieberman, "Enzymebased paper test for detection of lactose in illicit drugs," Analytical Methods, vol. 12, no. 8, pp. 1077-1084, 2020.

[26] A. K. Yetisen, N. Jiang, A. Tamayol et al., "Paper-based microfluidic system for tear electrolyte analysis," Lab on a Chip, vol. 17, no. 6, pp. 1137-1148, 2017.

[27] M. Su, L. Ge, S. Ge et al., "Paper-based electrochemical cytodevice for sensitive detection of cancer cells and in situ anticancer drug screening," Analytica Chimica Acta, vol. 847, pp. 1-9, 2014.

[28] S. I. Kaya, S. Kurbanoglu, E. Yavuz, S. Demiroglu Mustafov, F. Sen, and S. A. Ozkan, "Carbon-based ruthenium nanomaterial-based electroanalytical sensors for the detection of anticancer drug Idarubicin," Scientific Reports, vol. 10, no. 1, p. $11057,2020$.

[29] January 2021, https://www.felix-schoeller.com/en_en/home.html.

[30] J. Laketa, M. Radovanovic, T. Kojic et al., "Determination of elec-trical parameters of dried blood spot samples with different concentration of methotrexate," in Proceedings of 2017 IEEE East-West Design and Test Symposium, EWDTS, pp. 14, Novi Sad, Serbia, 2017.

[31] T. Kojić, G. Stojanović, A. Miletić, M. Radovanović, H. AlSalami, and F. Arduini, "Testing and characterization of different papers as substrate material for printed electronics and application in humidity sensor," Sensors and Materials, vol. 31, no. 9, pp. 2981-2995, 2019.

[32] O. A. Khan, A. D. Blann, M. J. Payne et al., "Continuous lowdose cyclophosphamide and methotrexate combined with celecoxib for patients with advanced cancer," British Journal of Cancer, vol. 104, no. 12, pp. 1822-1827, 2011.

[33] M. Colleoni, A. Rocca, M. T. Sandri et al., "Low-dose oral methotrexate and cyclophosphamide in metastatic breast cancer: antitumor activity and correlation with vascular endothelial growth factor levels," Annals of Oncology, vol. 13, no. 1, pp. 73-80, 2002.

[34] January 2021, https://pubchem.ncbi.nlm.nih.gov/compound/ Methotrexate\#section=Computed-Properties.
[35] January 2021, https://pubchem.ncbi.nlm.nih.gov/compound/ Cyclophosphamide\#section=Computed-Properties.

[36] M. Simic, L. Manjakkal, K. Zaraska, G. M. Stojanovic, and R. Dahiya, "TiO2 based thick film $\mathrm{pH}$ sensor," IEEE Sensors Journal, vol. 17, no. 2, pp. 248-255, 2017.

[37] M. Simic, T. Kojic, M. Radovanovic, G. M. Stojanovic, and H. Al-Salami, "Impedance spectroscopic analysis of the interidigitated flexible sensor for bacteria detection," IEEE Sensors Journal, vol. 20, no. 21, pp. 12791-12798, 2020.

[38] M. Simic and G. M. Stojanovic, "Compact electronic system for complex impedance measurement and its experimental verification," in 2017 European Conference on Circuit Theory and Design (ECCTD), pp. 1-4, Catania, Italy, September 2017. 